\title{
The evolutionary history of Drosophila buzzatii. XXXII. Linkage disequilibrium between allozymes and chromosome inversions in two colonizing populations
}

\author{
E. BETRÁN*, J. E. QUEZADA-DIAZ, A. RUIZ, M. SANTOS \& A. FONTDEVILA \\ Departament de Genètica i Microbiologia, Universitat Autònoma de Barcelona, 08193 Bellaterra (Barcelona), Spain
}

\begin{abstract}
Chromosome polymorphism in Drosophila buzzatii is under selection but the genes responsible for the effect of the inversions on fitness are unknown. On the other hand, there is evidence for selection on several allozyme loci but the presence of paracentric inversions on the second chromosome, where most of the polymorphic loci are located, complicates the interpretation. Studies of the associations between allozymes and inversions are thus necessary to help understand the effect of selection at both the chromosomal and allozymic level. Until now this kind of information has only been available in D. buzzatii for two loci, Est-1 and Est-2, in Australian populations. Here we describe the genetic constitution of two Old World populations, Carboneras and Colera. Emphasis has been placed on the analysis of the linkage disequilibria between the second chromosome arrangements and three allozyme loci, Est-2, Pept-2 and Aldox, located on this chromosome. In addition, the recombination frequencies between the loci, and between the loci and the inversion breakpoints, have been estimated and a genetic map of the three loci has been produced. The two populations differ in allele and arrangement frequencies, as well as in the pattern of one-locus disequilibria. Est-2 and Aldox are associated with the second chromosome arrangements in both populations. On the other hand, Pept-2 is associated with the inversions in Colera but not in Carboneras. The gametic associations among the three loci are discussed taking into account the position of these loci on the chromosome map and the lack of recombination in the heterokaryotypes.
\end{abstract}

Keywords: allozymes, cactophilic Drosophila, chromosome inversions, colonization, Drosophila buzzatii, linkage disequilibrium.

\section{Introduction}

The colonizing species Drosophila buzzatii (repleta group, buzzatii complex; Ruiz \& Wasserman, 1993) originated in South America but has spread within historical times to the Canary Islands, the Mediterranean region, Australia and several other places throughout the world (David \& Tsacas, 1980; Barker et al., 1985; Fontdevila, 1989). It is specific to the cactus niche and uses the decaying stems of several species of the genera Opuntia, Cereus and Trichocereus as feeding and breeding substrates (Fontdevila, 1981; Pereira et al., 1983; Hasson et al., 1992).

*Correspondence.
The karyotype of $D$. buzzatii consists of six pairs of chromosomes: four pairs of equal length acrocentric autosomes, one pair of dot chromosomes, a long acrocentric $\mathrm{X}$ and a small acrocentric $\mathrm{Y}$ chromosome (Wasserman, 1962). The second and fourth chromosomes are polymorphic for a total of eight paracentric inversions (Ruiz et al., 1984; Ruiz \& Wasserman, 1993). All the polymorphic inversions are present in South America (Fontdevila et al., 1982; Ruiz et al., 1984) whereas in the Old World populations only six arrangements $\left(2 \mathrm{st}, 2 \mathrm{j}, 2 \mathrm{jz}^{3}, 2 \mathrm{jq}^{7}, 4 \mathrm{st}\right.$ and $\left.4 \mathrm{~s}\right)$, have been recorded (Fontdevila et al., 1981; Fontdevila, 1989). All these arrangements, except $2 \mathrm{jq}^{7}$ and $4 \mathrm{~s}$, are also present in Australia (Knibb et al., 1987).

Several lines of research have provided evidence for an adaptive role of the inversion polymorphisms in $D$. 
buzzatii. (1) Experimental populations subject to different nutritional regimes exhibit rapid and consistent changes in arrangement frequencies (Ruiz \& Fontdevila, 1985; Ruiz et al., 1987). (2) Latitudinal clines in the frequencies of some inversions have been observed both in the original and colonized areas (Ruiz, 1982; Knibb et al., 1987). (3) An analysis of selection components carried out in Carboneras (Spain) indicated viability differences between the second chromosome karyotypes (Ruiz et al., 1986; Santos et al., 1989). (4) The second chromosome karyotypes have an effect, in both the field and the laboratory, on body size (Ruiz et al., 1991; Hasson et al., 1992), an adaptive trait which shows a positive correlation with adult fitness components in natural populations (Santos et al., 1988, 1992; Ruiz \& Santos, 1989). The effect of the karyotype on body size and fitness is thought to be caused by the association of different arrangements with particular alleles that influence these traits (Ruiz et al., 1991). The genes responsible, however, have not yet been identified.

The second chromosome, which carries the majority of rearrangements in $D$. buzzatii, also exhibits much greater allozyme variability than the remaining chromosomes (Barker, 1981; Quezada, 1993). Some studies have revealed that selection acts also on some of these allozyme loci. Perturbation experiments (Barker \& East, 1980; Barker et al., 1989), long-term temporal studies on variation in allele frequencies over time and correlation with environmental variables (Barker, 1981; Barker et al., 1986), studies of autocorrelation (Sokal et al., 1987), and experiments of heat and cold-shock resistance (Watt, 1981) suggest an adaptive value for the variation at the Est-1, Est-2, Pyr, Adh-1 and Aldox loci. In all these studies, the presence of polymorphic inversions on the second chromosome complicates interpretation because the detected allozyme frequency changes could result from selection acting in some way on the inversions rather than on the allozyme loci. It is thus clear that studies of linkage disequilibrium between allozymes and inversions are necessary to understand the adaptive significance of allozyme variability in $D$. buzzatii. Until now only one such study has been undertaken. Knibb et al. (1987) described the associations between Est-1 and Est-2 and the second chromosome arrangements in several Australian populations but no information is available for the Old World populations.

We describe here the inversion and allozyme polymorphisms in two populations of the Iberian Peninsula and the linkage disequilibria between the second chromosome arrangements and three allozyme loci, Est-2, Pept-2 and Aldox, located on this chromosome. Only limited information on the location and genetic distances among these genes is currently available (Schafer et al., 1993). Therefore, a genetic map of the three loci has been obtained and the recombination frequencies between the loci, and between each locus and the inversion breakpoints, have been estimated. When analysing the linkage disequilibrium between loci linked to inversions, the absence of recombination in the heterokaryotypes must be taken into account (Zouros \& Krimbas, 1973). Thus, we partitioned the total disequilibrium between two loci into different components: within and between chromosome arrangements (A. Navarro et al., unpublished data). The genetic constitution of the two Old World populations is discussed in relation to colonization.

\section{Materials and methods}

\section{Natural populations studied and processing of the samples}

Two colonized populations of Drosophila buzzatii in the Old World, Carboneras $\left(37^{\circ} \mathrm{N} 1.9^{\circ} \mathrm{W}\right)$ and Colera $\left(42.37^{\circ} \mathrm{N} 3.16^{\circ} \mathrm{E}\right)$, were sampled. Both are located on the Mediterranean coast of the Iberian Peninsula but differ in several respects. The collecting site in Carboneras (Almería, S.E. Spain) is an abandoned Opuntia ficus-indica (prickly pear) plantation situated in a hot and dry region (see Ruiz et al., 1986 for a detailed description). The genetic constitution and structure of this population has been previously studied in detail (Fontdevila et al., 1981; Ruiz et al., 1986; Santos et al., 1989; Quezada-Díaz et al., 1992; Barbadilla et al., 1994). Although there are large fluctuations in the number of adults over the seasons, the population is without any doubt a permanent one and the effective population number is likely to be high (Santos et al., 1989).

Colera (Girona, N.E. Spain), on the other hand, is located in a torrent on the northern Mediterranean coast. A cactus species, tentatively identified as Opuntia dillenii (Britton \& Rose, 1963; Backeberg, $1977)$, grows along a dry river bed and is scattered over a strip about $25 \mathrm{~m}$ wide and $1 \mathrm{~km}$ long. A few $O$. ficus-indica plants are also present on the nearby hillsides. D. buzzatii larvae have been observed in rotting $O$. dillenii fruits. The region is quite humid (with an average rainfall of $1000 \mathrm{~mm}$ per year). However, the general vegetation is low because of the strong and cold wind coming from the sea. Winter is relatively cold (the average temperature during January is $8^{\circ} \mathrm{C}$ ). In July 1991,5 days of intensive collecting with banana baits and aspirating from Opuntia rots yielded 601 adults. In a second collection next autumn (31 October and 5 November 1991), only 10 females and 
20 males could be caught. Thus, the size of this population is small and suffers a marked reduction during the autumn-winter season. We do not know at the moment whether the population is permanent or is recolonized every spring from refugia in the nearby area.

Over 1000 adults were collected in Carboneras between 14 July and 16 July 1990 by means of banana baits scattered throughout the sampling area. Males were individually crossed with 4-5-day-old virgin females from a $D$. buzzatii stock fixed for inversion $2 \mathrm{j}$ and alleles Est-2 ${ }^{a}$ and Pept- $2^{b}$ (see below). One thirdinstar larva from the $F_{1}$ of each cross was dissected in saline solution and the salivary gland chromosomes prepared as described in Fontdevila et al. (1981). Following Knibb et al. (1987), we also analysed electrophoretically the genotypes at the Est-2 and Pept2 loci of the same larvae (using the rest of the body). In this way, we determined, in a sample of gametes, the arrangements present on the second chromosome as well as the alleles at the Est-2 and Pept-2 loci. In addition, wild-caught males were genotyped for Aldox, Adh-1, Pept-2 and Est-2 by means of electrophoresis.

The population of Colera was sampled from 16 July to 19 July 1991 . All the adults, 365 males and 236 females, were individually crossed with virgin flies of the opposite sex from a stock fixed for arrangement $2 \mathrm{jz}{ }^{3}$ and alleles Est $-2^{d}$ and Pept $-2^{b}$. Wild females were kept in mass cultures for a week to allow them to lay any fertilized eggs that they might have been carrying. In addition, the cross females were transferred every 2 days to new vials with fresh food, and the first vial of each cross was discarded altogether. This experimental procedure, because of sperm predominance in $D$. buzzatii (Barbadilla et al., 1991), reduces the possibility of wild-fathered larvae in the analysed sample. Allele Est-2 ${ }^{d}$, missing in the population of Colera, provided a further test for the correct paternity of the analysed larvae. $F_{1}$ larvae were analysed as above to determine the gametic frequencies for the second chromosome, and the Est-2 and Pept-2 loci. Gametic disequilibria between Pept-2, Est-2 and Aldox were studied using $F_{1}$ adults because aldehydo-oxidase only shows enough activity in the adult stage. In addition, wild adults were genotyped for Est-2, Pept-2 and Adh-1.

\section{Allozyme electrophoresis}

Four allozymic loci, Est-2, Pept-2, Aldox and Adh-1 that encode for soluble enzymes, were analysed by horizontal starch gel electrophoresis (see QuezadaDíaz et al., 1992, for details of electrophoretic techniques). The four loci have been found previously to be polymorphic in Carboneras (Quezada-Diaz et al.,
1992). Recently, five alleles have been detected for Est2 in Carboneras $\left(E s t-2^{a}, E s t-2^{b}, E s t-2^{c+}, E s t-2^{c}\right.$ and Est-2d $)$ and all except Est-2 $2^{d}$ in Colera. Under our electrophoretic conditions, alleles Est-2 ${ }^{b}$ and Est-2 ${ }^{c+}$ show very close bands in the zymograms. Therefore these two alleles were not distinguished in our previous work (under $E s t-2^{b}$ in Quezada-Díaz et al., 1992) and in some of the samples here (under Est-2 ${ }^{b *}$ ).

\section{Genetic map of the second chromosome}

Est-2, Aldox and Pept-2 are located on the second chromosome (Schafer et al., 1993; this work) while Adh-1 has been mapped to the third chromosome (Labrador et al., 1990). The three loci located on the second chromosome were mapped using $D$. buzzatii stocks fixed for different arrangements and allele combinations. Three-point tests were carried out to determine the linear relationships and the relative distances among the three loci both in the $2 \mathrm{st}$ and $2 \mathrm{j}$ gene arrangments. The distances from Est-2 and Pept2 to the breakpoints of inversions $2 \mathrm{j}$ and $2 \mathrm{q}^{7}$ were also estimated. Recombination frequencies and their standard errors were obtained following Elandt-Johnson (1971, pp. 427-431). Because we are most interested in the consequences at the population level, recombination frequencies were taken directly as estimates of genetic distance without transformation by means of a mapping function.

\section{Data analysis}

Deviations from Hardy-Weinberg expectations were measured using the one-locus disequilibrium coefficients $\left(D_{A}{ }^{i j}\right)$, and each statistically independent coefficient was tested with a $\chi^{2}$ statistic (Weir, 1990, pp. 71-89). For a multiallelic locus, the departure of the total number of heterozygotes from the expected number can also be tested by a $\chi^{2}$, test, although this is a conservative procedure (Pamilo \& Varvio-Aho, 1984). Gametic disequilibrium was measured using the $D$ coefficient of Lewontin \& Kojima (1960). For multiallelic loci, each statistically independent coefficient was tested using the $\chi^{2}$ statistic (Weir, 1990, p. 93). The overall hypothesis that none of the statistically independent coefficients is different from zero was tested using the $\chi_{\text {T }}^{2}$ test (Weir, 1990, p. 94), which is equivalent to a contingency table.

The analysis of the gametic disequilibrium between two loci, $A$ and $B$, is complicated when they are linked to polymorphic chromosome inversions. The total disequilibrium between $A$ and $B$ can be partitioned into 'within arrangements' and 'between arrangements' components (A. Ruiz et al., 1991 and unpublished 
data). In the particular case of a population polymorphic for four chromosome arrangements, as Carboneras and Colera, this partition is:

$D_{A B}^{i j}=$

$u_{1} D_{A B\left(C_{1}\right)}^{i j}+u_{2} D_{A B\left(C_{2}\right)}^{i j}+u_{3} D_{A B\left(C_{3}\right)}^{i j}+u_{4} D_{A B\left(C_{4}\right)}^{i j}$

$+\frac{D_{A C_{1}}^{i} D_{B C_{1}}^{j}}{u_{1}}+\frac{D_{A C_{2}}^{i} D_{B C_{2}}^{j}}{u_{2}}+\frac{D_{A C_{3}}^{i} D_{B C_{3}}^{j}}{u_{3}}+\frac{D_{A C_{4}}^{i} D_{B C_{4}}^{j}}{u_{4}}$,

where $u_{k}(k=1, \ldots, 4)$ is the frequency of the arrangement $C_{k} ; D_{A B}^{i{ }^{\prime}}\left(C_{k}\right)$ is the disequilibrium coefficient between the $i$ th and the $j$ th alleles of loci $A$ and $B$, respectively, within arrangement $C_{k}$; and $D_{A C_{k}}^{i}\left(D_{B C_{k}}^{j}\right)$ is the disequilibrium between allele $i(j)$ of locus $A(B)$ and the gene arrangement $C_{k}$. This partition of the total disequilibrium is necessary for interpreting the origin of the disequilibria because in a random mating population each component decays at a different rate (A. Navarro et al., unpublished data). In general, the within arrangements disequilibria decay at a faster rate than the between arrangements disequilibria. Therefore, stronger associations are expected between allozymes and inversions than between allozymes within chromosome arrangements.

Three-locus disequilibria as defined by Bennet (1954) were also estimated in some cases. Relative disequilibria $\left(D^{\prime}\right)$ were calculated following Lewontin (1964) for the pair-wise disequilibria, and following Robinson et al. (1991) for the three-locus disequilibria. Weir (1990) provides a way of testing the three-locus disequilibria (note that the square root in his formula on p. 96 for the corresponding $\chi^{2}$ statistic must be misprinted, c.f. with Appendix C, p. 306).
All data analyses were carried out using the CSSStatistica package run on a PC-compatible or using the BMDP Statistical Software run on a Vax-6610 VMS at the Centre de Càlcul of the Universitat Autonoma de Barcelona. Three-locus disequilibria were calculated and tested using computer program TLD written in Q BASIC by J. M. Ranz.

\section{Results}

\section{Genetic map of the Est-2, Aldox and Pept-2 loci}

Figure 1 summarizes the information obtained for the genetic map. Est-2 and Pept-2 were found to be the most distant markers, on both the $2 \mathrm{st}(\mathrm{RF}=50.5 \pm 6.8)$ and the $2 \mathrm{j}$ chromosomes $(\mathrm{RF}=46.5 \pm 5.8)$, and to segregate independently. Aldox is located in between on both the $2 \mathrm{st}$ and $2 \mathrm{j}$ gene arrangements. In addition, Est-2 must be close to the proximal breakpoint of inversion $2 \mathrm{j}$ and within the $2 \mathrm{q}^{7}$ region as no recombinants were detected with either inversion. On the other hand, Pept-2 must be located on a distal position as recombinants between Pept-2 and inversions $2 \mathrm{j}$ and $2 q^{7}$ were observed.

\section{Gene and genotypic frequencies and one-locus disequilibria}

Table 1 gives the arrangement frequencies obtained from the gametes derived from wild-caught flies. At Carboneras, the frequencies were similar to those reported in earlier collections (Fontdevila et al., 1981; Ruiz et al., 1986, 1991). Although the same polymorphic inversions are present in both populations,
Fig. 1 Genetic map on arrangements 2 st and $2 \mathrm{j}$ of loci Aldox, Pept-2 and Est-2 in the species Drosophila buzzatii. Frequencies of recombination $(\mathrm{RF})$ and their 95 per cent confidence intervals are given.

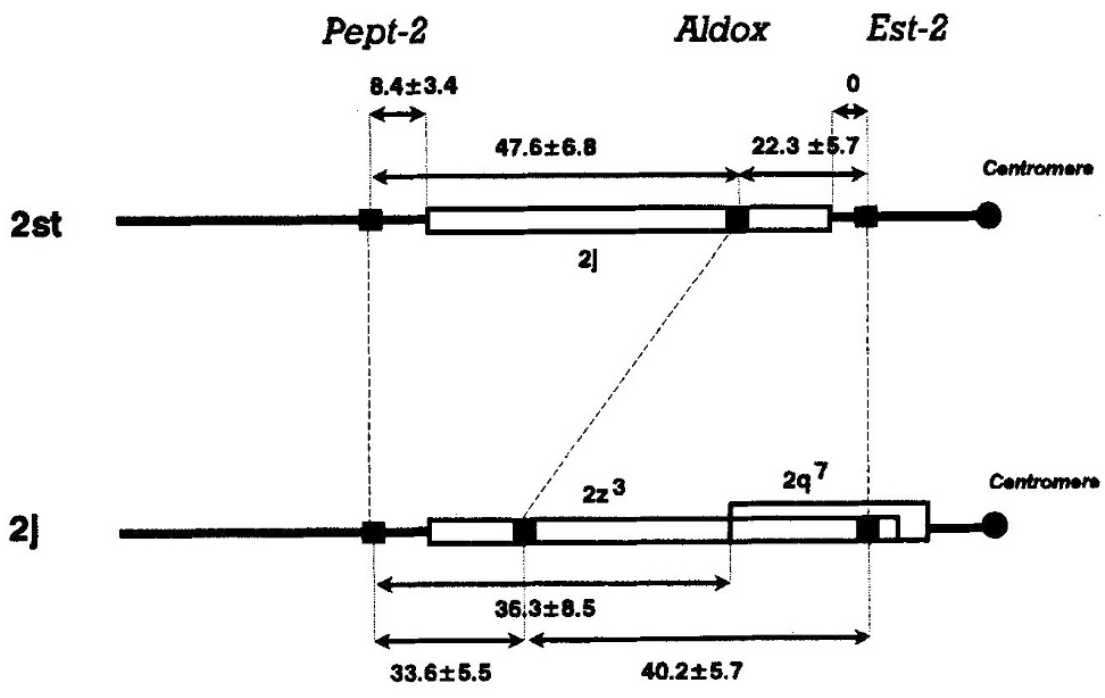


Table 1 Arrangement frequencies for the second and fourth chromosomes in two samples of Drosophila buzzatii collected in Carboneras and Colera (Spain)

\begin{tabular}{|c|c|c|c|c|c|}
\hline \multirow[b]{2}{*}{ Arrangement } & \multirow{2}{*}{$\frac{\text { Carboneras }}{\text { Males }}$} & \multicolumn{2}{|c|}{ Colera } & \multicolumn{2}{|c|}{$\chi^{2}$ for differences between } \\
\hline & & Males & Females & Sexes & Populations \\
\hline $2 \mathrm{st}$ & 0.4289 & 0.1311 & 0.1649 & \multirow{4}{*}{$\begin{array}{c}1.90 \\
\text { (d.f. }=3)\end{array}$} & \multirow{4}{*}{$\begin{array}{c}103.03^{* * *} \\
(\text { d.f. }=3)\end{array}$} \\
\hline $2 j$ & 0.3807 & 0.4909 & 0.4433 & & \\
\hline $2 \mathrm{jz}^{3}$ & 0.1548 & 0.2652 & 0.2887 & & \\
\hline $2 \mathrm{jq}^{7}$ & 0.0356 & 0.1128 & 0.1031 & & \\
\hline$N$ & 394 & 328 & 194 & \multirow{4}{*}{$\begin{array}{c}0.98 \\
\text { (d.f. }=1)\end{array}$} & \multirow{4}{*}{$\begin{array}{l}31.27^{* * *} \\
(\text { d.f. }=1)\end{array}$} \\
\hline $4 \mathrm{st}$ & 0.7584 & 0.5640 & 0.6082 & & \\
\hline $4 s$ & 0.2416 & 0.4360 & 0.3917 & & \\
\hline$N$ & 389 & 328 & 194 & & \\
\hline
\end{tabular}

${ }^{* * *} P \leqslant 0.001$.

noticeably lower frequencies of the standard arrangements (2st and 4st) were found in Colera. No differences between sexes were detected at Colera.

Allele frequencies for Aldox, Adh-1, Pept-2 and Est2 in Carboneras and Colera are given in Table 2. All the data in this table come directly from the genotypes of wild adults, except the allele frequencies for Aldox in Colera which come from the sample of gametes. Only $A d h-1$ shows significantly different frequencies between the sexes in Colera. When allele frequencies were compared between Carboneras and Colera all tests yielded highly significant results. Alleles Aldox ${ }^{a}$, Adh-1 ${ }^{b}$, Pept $-2^{a}, E s t-2^{b *}$ and Est- $2^{c}$ have higher frequencies in Colera than in Carboneras.

In Carboneras, there was an excess of heterozygotes (negative $D_{A}$ values) at all four loci, but only that for Est-2 was significant (Table 2). By contrast, the majority of $D_{A}$ values in Colera were positive, i.e. homozygotes were in excess, and those for Est-2 in males and females and that for $A d h-1$ in males were significant (Table 2).

\section{Gametic frequencies and linkage disequilibria}

Gametic frequencies for Est-2, Pept-2 and the second chromosome arrangements in Carboneras and Colera reflect departure from linkage equilibrium in both populations: out of 32 possible haplotypes only 14 were present in Carboneras and 10 in Colera. Contingency $\chi^{2}$ tests for the three pair-wise combinations gave the following results: Est-2 alleles are strongly associated with the second chromosome arrangements in both populations (Carboneras: $\chi_{9}^{2}=431.82$; Colera: males $\chi_{9}^{2}=881.92$; females $\chi_{9}^{2}=539.97 ; P<0.001$ in all three comparisons); Pept-
2 was associated with the second chromosome arrangements in the population of Colera but not in Carboneras (Carboneras: $\chi_{3}^{2}=0.43 \mathrm{NS}$; Colera: males $\chi_{3}^{2}=28.14$; females $\chi_{3}^{2}=13.50$ and $P<0.001$ in both sexes). Finally, Est-2 and Pept-2 were significantly associated in both populations (Carboneras: $\chi_{3}^{2}=9.01$, $P<0.05$; Colera: males $\chi_{3}^{2}=23.32, P<0.001$; females $\left.\chi_{3}^{2}=8.92, P<0.01\right)$. Results of the partition of the disequilibria within and between inversions are given in Table 3. The analysis was carried out separately for each population and sex because, owing to the lack of recombination in Drosophila males, haplotype frequencies in the gametes produced by the two sexes may differ. In this table four values for each disequilibrium parameter, corresponding to the four Est-2 alleles, are given.

Within arrangement disequilibria had, in general, very low and nonsignificant values. The only single exception was the disequilibrium within arrangement $2 \mathrm{jz}^{3}, D_{A B(2 \mathrm{jz} 3)}$, in the Carboneras sample with the combination of alleles Est- $2^{c}$ and Pept-2 ${ }^{a}$ in excess. Disequilibria between Est-2 alleles and second chromosome arrangements were highly significant in both populations but, comparing the $D^{\prime}$ values, Colera shows even stronger disequilibria than Carboneras. The 2st arrangement contains two alleles, Est- $2^{a}$ (in excess) and $E s t-2^{b *}$, in the population of Carboneras, but only one, Est-2a $2^{a}$ in Colera. On the other hand, the $2 \mathrm{j}$ arrangement holds both alleles in both populations but with $E s t-2^{b *}$ in excess and $E s t-2^{a}$ in deficit. The $2 \mathrm{jz} \mathrm{z}^{3}$ arrangement harbours alleles Est $-2^{c}$ and Est-2d in Carboneras and only Est $2^{c}$ in Colera. Finally, in Colera the $2 \mathrm{jq}^{7}$ arrangement is fully associated with allele Est $-2^{c+}$. In Carboneras this arrangement was found to contain the $E s t-2^{b *}$ allele which, as noted 
Table 2 Allele frequencies of Aldox, Adh-1,Pept-2 and Est-2, in two samples of wild Drosophila buzzatii adults collected in Carboneras and Colera (Spain). Intralocus disequilibrium coefficients $(D)$ and sample sizes of individuals $(N)$ are also given

\begin{tabular}{|c|c|c|c|c|c|c|}
\hline \multirow[b]{2}{*}{ Locus } & \multirow[b]{2}{*}{ Allele $\dagger$} & \multirow{2}{*}{$\frac{\text { Carboneras }}{\text { Males }}$} & \multicolumn{2}{|c|}{ Colera } & \multicolumn{2}{|c|}{$\chi^{2}$ for differences between } \\
\hline & & & Males & Females & Sexes & Populations \\
\hline \multirow[t]{3}{*}{ Aldox } & $\begin{array}{l}a \\
b\end{array}$ & $\begin{array}{l}0.6951 \\
0.3049\end{array}$ & $\begin{array}{l}0.8613 \\
0.1387\end{array}$ & & & $\begin{array}{l}25.04^{* * *} \\
\text { (d.f. }=1 \text { ) }\end{array}$ \\
\hline & $D$ & -0.014 & & & & \\
\hline & $N$ & 328 & 238 & & & \\
\hline \multirow[t]{3}{*}{ Adh-1 } & $\begin{array}{l}b \\
c\end{array}$ & $\begin{array}{l}0.5887 \\
0.4113\end{array}$ & $\begin{array}{l}0.8090 \\
0.1910\end{array}$ & $\begin{array}{l}0.8719 \\
0.1281\end{array}$ & $\begin{array}{c}4.72^{*} \\
(\text { d.f. }=1)\end{array}$ & $\begin{array}{l}71.82^{* * *} \\
(\text { d.f. }=1)\end{array}$ \\
\hline & $D$ & -0.011 & $0.026^{* *}$ & 0.017 & & \\
\hline & $N$ & 355 & 288 & 121 & & \\
\hline \multirow[t]{3}{*}{ Pept-2 } & $\begin{array}{l}a \\
b\end{array}$ & $\begin{array}{l}0.4465 \\
0.5535\end{array}$ & $\begin{array}{l}0.4971 \\
0.5029\end{array}$ & $\begin{array}{l}0.4954 \\
0.5046\end{array}$ & $\begin{array}{c}0.00 \\
(\text { d.f. }=1)\end{array}$ & $\begin{array}{c}4.50^{*} \\
(\text { d.f. }=1)\end{array}$ \\
\hline & $D$ & -0.002 & -0.024 & 0.009 & & \\
\hline & $N$ & 374 & 345 & 220 & & \\
\hline \multirow[t]{4}{*}{ Est-2 } & $\begin{array}{c}a \\
b^{*} \\
c \\
d\end{array}$ & $\begin{array}{l}0.5818 \\
0.2961 \\
0.0896 \\
0.0325\end{array}$ & $\begin{array}{c}0.2098 \\
0.5045 \\
0.2857 \\
-\end{array}$ & $\begin{array}{l}0.2296 \\
0.4975 \\
0.2729 \\
-\end{array}$ & $\begin{array}{c}4.36 \\
(\mathrm{~d} . \mathrm{f} .=2)\end{array}$ & $\begin{array}{c}229.19^{* * *} \\
(\text { d.f. }=3)\end{array}$ \\
\hline & $D_{\mathrm{T}}$ & $-0.036^{* * *}$ & $0.036^{* *}$ & $0.030^{* *}$ & & \\
\hline & $\begin{array}{c}D_{a b^{*}} \\
D_{a c} \\
D_{a d} \\
D_{b^{*} c} \\
D_{b^{*} d} \\
D_{c d}\end{array}$ & $\begin{array}{c}-0.030^{* *} \\
-0.015^{* * *} \\
-0.010^{* *} \\
0.010^{*} \\
0.006^{*} \\
0.003\end{array}$ & $\begin{array}{l}0.028^{* *} \\
0.005 \\
- \\
0.003 \\
- \\
-\end{array}$ & $\begin{array}{c}0.033^{*} \\
-0.019 \\
- \\
0.016 \\
- \\
-\end{array}$ & & \\
\hline & $N$ & 385 & 336 & 196 & & \\
\hline
\end{tabular}

For Aldox Colera males, $N$ is the number of gametes.

$\dagger$ Allele $b^{*}$ of the Est-2 locus stands for alleles $b$ and $c+$ pooled (see text).

${ }^{*} P \leqslant 0.05,{ }^{* *} P \leqslant 0.01,{ }^{* * *} P \leqslant 0.001$.

above, results from pooling $E s t-2^{b}$ and $E s t-2^{c+}$. A recent analysis of six $2 \mathrm{st}$ and six $2 \mathrm{j}$ isochromosomal lines extracted from Carboneras has shown that none of them contains the Est-2 ${ }^{c+}$ allele, whereas six $2 \mathrm{jq}^{7}$ lines from the same population hold only this allele. Therefore, the total association between the $2 \mathrm{jq}^{7}$ arrangement and the Est-2 ${ }^{c+}$ allele observed in Colera is very likely to be the same in both populations. Disequilibria between Pept-2 and the second chromosome arrangements were nonsignificant in Carboneras but highly significant in Colera, where Pept-2 ${ }^{a}$ was associated with the 2st arrangement in both sexes.

In Carboneras, total disequilibria between Est-2 and Pept-2 were in general low and nonsignificant, as expected from the lack of disequilibria within arrange- ments and the lack of association between Pept-2 and the second chromosome arrangements. Only the combination between alleles Est-2 $2^{d}$ and Pept- $2^{a}$ exhibited a significant deficit chiefly resulting from the disequilibrium shown by this combination within the $2 \mathrm{jz}^{3}$ arrangement. In Colera, two of the four disequilibria between Est-2 and Pept-2 in males were significant: Pept $-2^{a}$ was found in excess in combination with $E s t-2^{a}$, and in deficiency when combined with Est $-2^{c}$. The former allele combination showed a significant excess also in females. These total disequilibria result chiefly from the between arrangements component and match closely the pattern of associations observed between Pept-2 and the chromosome inversions because the association between Est-2 and the inver- 


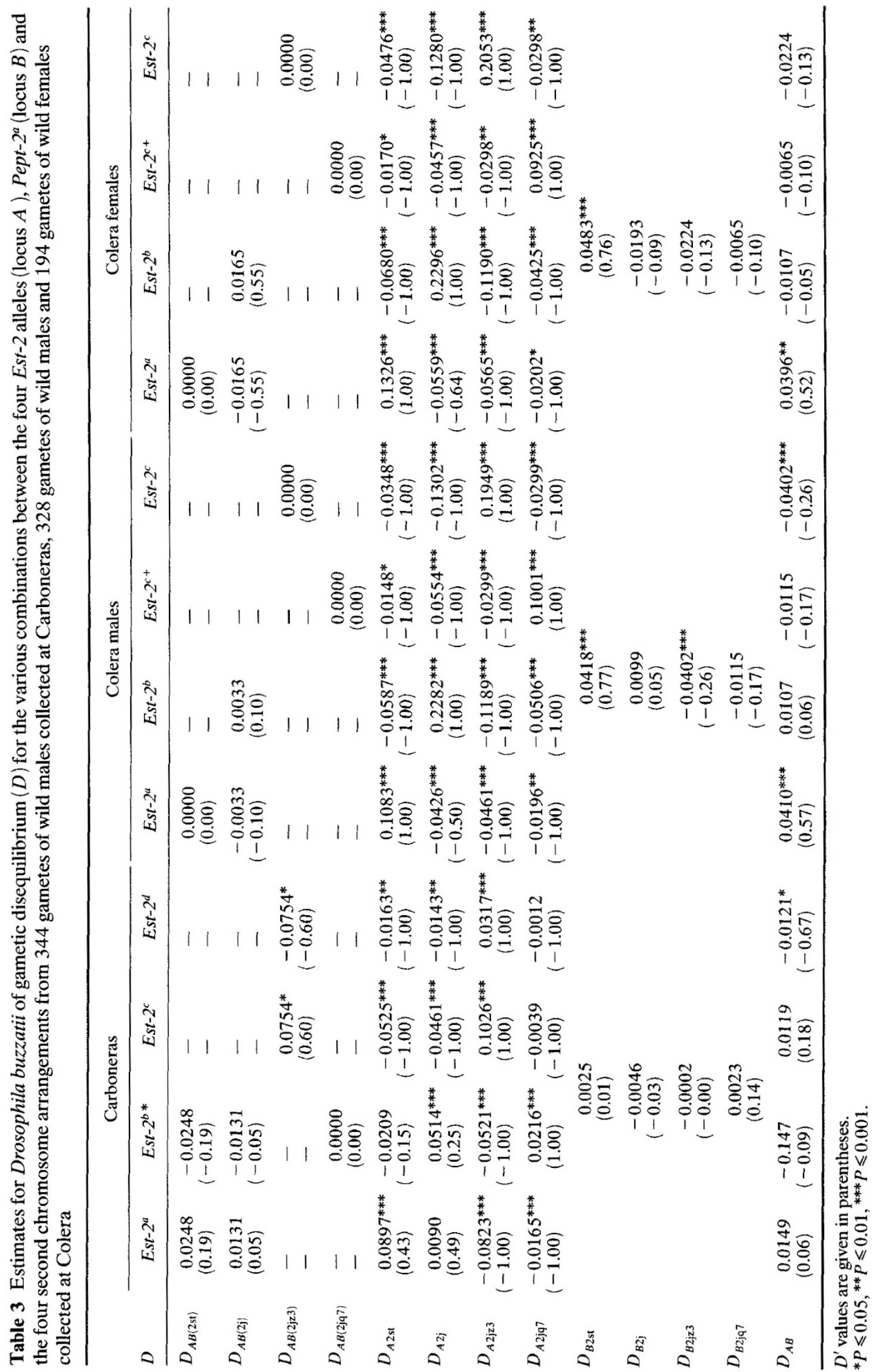


Table 4 Gametic disequilibria $(D)$ between Est-2 (locus $A$ ), Pept-2 ${ }^{a}($ locus $B)$ and Aldox ${ }^{a}$ (locus $C$ ) estimated from 238 gametes derived from wild Drosophila buzzatii males collected in Colera (Spain)

\begin{tabular}{lcccc}
\hline \multicolumn{5}{c}{ Allele of the Est-2 locus } \\
\cline { 2 - 5 }$D$ & Est - $^{a}$ & Est $-2^{b *}$ & Est $-2^{c}$ & $\chi_{\mathrm{I}}^{2}$ \\
\hline$D_{A B}$ & $0.0558^{* * *}$ & -0.0059 & $-0.0499^{* * *}$ & $19.90^{* * *}$ \\
& $(0.505)$ & $(-0.027)$ & $(-0.426)$ & $($ d.f. $=2)$ \\
$D_{A C}$ & $-0.0704^{* * *}$ & $0.0356^{* *}$ & $0.0348^{* * *}$ & $64.46^{* * *}$ \\
& $(-0.626)$ & $(0.485)$ & $(0.892)$ & $($ d.f. $=2)$ \\
$D_{B C}$ & & $-0.0474^{* * *}$ & & $18.40^{* * *}$ \\
& & $(-0.585)$ & & $($ d.f. $=1)$ \\
$D_{A B C}$ & $-0.0271^{* * *}$ & $0.0232^{* * *}$ & 0.0040 & $46.83^{* * *}$ \\
& $(-0.625)$ & $(0.625)$ & $(0.000)$ & $($ d.f. $=2)$ \\
\hline
\end{tabular}

Relative disequilibria $\left(D^{\prime}\right)$ are given in parentheses.

Est $-2^{b *}$ stands for alleles Est $-2^{b}$ and Est-2 ${ }^{c+}$ pooled.

${ }^{*} P \leqslant 0.05,{ }^{* *} P \leqslant 0.01,{ }^{* * *} P \leqslant 0.001$.

sions is virtually at its maximum (see the $D^{\prime}$ values in Table 3).

Pair-wise disequilibria and three-locus disequilibria parameters for the sample of $F_{1}$ adults are given in Table 4 . Most $D$ values were highly significant. Those between Est-2 and Pept-2 were, as expected, very similar to the disequilibria found by analysing a sample of $\mathrm{F}_{1}$ larvae. In addition, Aldox showed strong disequilibria with both Est-2 and Pept-2 because of a deficiency of Aldox $x^{a} /$ Est $^{a} 2^{a}$ and Aldox ${ }^{a} /$ Pept $^{-2}{ }^{a}$ gametes.

\section{Discussion}

The two populations of Drosophila buzzatii studied here, Carboneras and Colera, belong to the primary colonization area of the Old World (Fontdevila et al., 1981). They are at most 300 years old, but could be much more recent, especially Colera, as colonization of the Iberian Peninsula by $D$. buzzatii began from the south (Fontdevila et al., 1981). All the chromosome arrangements and all but one of the allozyme alleles found in Carboneras are also present in Colera. Est- $2^{d}$ is relatively rare $(p=0.03)$ in Carboneras and its absence from Colera may be simply a result of the founder effect or drift. The similar polymorphism observed in the two populations is probably a result of gene flow, at the present time or in the recent past, between populations along the Mediterranean coast of the Iberian Peninsula (Fontdevila et al., 1981; Fontdevila, 1989) and selection. The differences in arrangement frequencies observed agree well with the described latitudinal clines in the frequencies of some second chromosome arrangements. The frequency of 2 st correlates negatively with latitude $(r=-0.52$, $P<0.05)$ in a set of Old World and New World populations (Ruiz, 1982), and in Australia $(r=-0.42$, $P<0.10)$ (Knibb \& Barker, 1988). The Australian populations also show a positive and significant correlation with latitude for $2 \mathrm{jz}^{3} \quad(r=0.56, P<0.05)$. Furthermore, adults with the 2 st or 4 st arrangements have, on average, a smaller body size than those carrying inversions (Ruiz et al., 1991; Hasson et al., 1992; Betrán, 1992). Because in Drosophila body size usually increases with latitude (Prevosti, 1955; David \& Bocquet, 1975) the observed differences in arrangement frequencies between Colera and Carboneras fit well with the latitudinal clines and the effect of inversions on body size.

The marked differences between Carboneras and Colera in allele frequencies may be explained in part by the association with the arrangements. Est- $2^{a}$ has a much lower frequency in Colera than in Carboneras. This difference results from the association between Est $-2^{a}$ and the 2 st arrangement, but not entirely. The frequency of $E s t-2^{a}$ is greater in Colera than in Carboneras within arrangement 2 st $(100$ per cent vs. 72.3 per cent; $\left.\chi_{1}^{2}=24.5, P<0.001\right)$ whereas it is smaller within arrangement $2 \mathrm{j}$ ( 8.1 per cent vs. 53.8 per cent; $\left.\chi_{1}^{2}=97.48, P<0.001\right)$. These changes may be more parsimoniously attributed to drift or founder effect because a different pattern $\left(E s t-2^{a}\right.$ decreasing with latitude within 2 st) has been observed by Knibb \& Barker (1988) in Australia. Pept- $2^{a}$ has a higher 
frequency in Colera than in Carboneras. Changes in arrangement frequencies do not explain this difference because Pept-2a is associated with 2 st. A detailed analysis for Aldox is not possible because no direct estimates of the association between Aldox and the second chromosome inversions were obtained. Adh- $1^{b}$ also presents a higher frequency in Colera than in Carboneras independent of inversions that fits quite well the spatial pattern described for this allele in Australia (Sokal et al., 1987). In addition, Adh- 1 is the only locus which showed a significant difference between the sexes, in agreement also with previous observations in Australia (Barker, 1981; Barker et al., 1986), supporting the idea that variation at $A d h-1$ has an adaptive value in $D$. buzzatii.

A different pattern of departures from Hardy-Weinberg is found in the two populations. The excess of heterozygotes shown by the sample of Carboneras was also found in 1987 and 1989 (Quezada-Díaz et al., 1992; Quezada-Díaz, 1993) for some loci located on the second chromosome. Santos (1994) has suggested that multiple niche selection acting on the inversion polymorphism in viability could account for this excess. The general deficiency of heterozygotes observed in Colera (significant for Est-2 and $A d h-1)$ can be explained by a number of factors: null alleles, Wahlund effect, diversifying selection and inbreeding, among others (Gaffney et al., 1990; Santos, 1994). Deficiencies of heterozygous have been repeatedly observed in the Australian populations of D. buzzatii (Barker et al., 1986) and interpreted as inbreeding combined, for some loci, with selection. As inbreeding affects all loci equally, heterozygote deficiencies from inbreeding should be the same for all loci and alleles. This hypothesis of homogeneity has been tested by comparing deficiencies among loci treating inbreeding coefficients as correlation coefficients (Crow \& Kimura, 1970) and testing them accordingly (Sokal \& Rohlf, 1981). Inbreeding coefficients were not homogeneous among loci (males: $F_{\text {Adh }}$ $1=0.17 ; \quad F_{\text {Pept-2 }}=-0.10 ; \quad F_{\text {Est }-2}=0.12 ; \quad$ females: $F_{\text {Adh }-1}=0.15 ; \quad F_{\text {Pept-2 }}=0.04 ; \quad F_{\text {Est-2 }}=0.09 ; \quad$ with $\left.\chi_{5}^{2}=14.57, P<0.05\right)$. In addition, heterogeneity of inbreeding coefficients was tested within the multiallelic Est-2 locus. This was performed by means of a goodness of fit test of the observed genotype frequencies to those expected fitting a single inbreeding coefficient (Gaffney et al., 1990). This test gave significant results in females $\left(F=0.094 ; \chi_{2}^{2}=7.58, P<0.05\right)$ but not in males $\left(F=0.117 ; \chi_{2}^{2}=4.84, P>0.05\right)$. These results show that inbreeding cannot be the sole explanation of our observations and that selection is likely to play a role or even be the sole cause of the observed deficiencies (Santos, 1994).
Significant gametic associations between Est-2 alleles and second chromosome inversions were found in both populations. The association is nearly complete because each chromosome arrangement harbours only one or two Est-2 alleles. The most parsimonious explanation for these locus-inversion associations is a historical origin coupled with the lack of recombination in the heterokaryotypes (Ishii \& Charlesworth, 1977; Nei \& Li, 1980) although they are consistent also with a selective role of the Est-2 variation (Charlesworth, 1974). Nevertheless, the fact that the associations found in Colera and Carboneras are different from those described in the Australian populations (Knibb et al., 1987) suggests an important role of founder events during colonization. Founder effect or drift probably also explain the stronger association Est-2-inversion observed in Colera. It would be very interesting to have information about the gametic disequilibria in the original populations of Argentina and Bolivia.

Pept-2 shows a significant linkage disequilibrium with the second chromosome inversions only in Colera. Effective recombination frequencies (taking into account the lack of recombination in Drosophila males) between Pept-2 and the inversion breakpoints are relatively high: 4.2 per cent (with $2 \mathrm{j}$ and $2 \mathrm{z}^{3}$ ) and 18.15 per cent (with $2 q^{7}$ ). With this amount of recombination, these associations should not be expected unless this locus were involved in epistatic fitness effects (Nei \& Li, 1980) or the population suffers strong bottlenecks. The association found in Colera could be generated by random chance if this population were repopulated every year or suffers bottlenecks, in the same way as if the population had a small effective size all the year (Montchamp-Moreau \& Katz, 1986). An alternative explanation for the observed Pept-2-inversions associations observed in Colera could be that higher levels of linkage disequilibrium from overdominance are theoretically expected in small populations in comparison to large ones (Slatkin, 1977; Yamazaki, 1977; Yamaguchi et al., 1980). At present, no firm conclusions can be reached on the origin of the Pept-2 inversion disequilibria.

A significant association between Est-2 and Pept-2 was found in both populations but from different causes. In Carboneras, the negative association between $E s t-2^{d}$ and Pept $-2^{a}$ results exclusively from the within chromosome arrangements component: these two loci are associated within the $2 \mathrm{jz}^{3}$ arrangement. The effective recombination fraction for the disequilibrium within a given chromosome arrangement equals $u_{i} c_{i}$, where $u_{i}$ is the frequency of the arrangement and $c_{i}$ is the recombination fraction in the corresponding homokaryotypes (A. Navarro et al., unpublished data). 
In the $2 \mathrm{jz}^{3}$ arrangement, Est-2 comes closer to Pept-2. A preliminary estimate of 26 per cent $(N=46)$ for the recombination rate between Est-2 and Pept-2 in the $2 \mathrm{jz}^{3} / \mathrm{jz}^{3}$ homokaryotypes has been obtained (J. E. Quezada-Díaz, personal communication). Taking into account the fact that Drosophila males do not recombine, we can estimate the effective recombination frequency for the disequilibrium within $2 \mathrm{jz}^{3}$ as 2 per cent. This value is small enough to generate this disequilibrium by drift, especially if we consider that the effective population size for arrangement $2 \mathrm{jz}^{3}$ will be six times lower than that of the population as a whole. At Colera, on the other hand, the association between Est-2 and Pept-2 results exclusively from the between chromosome arrangements component, i.e. it is a simple consequence of the associations between each of these two loci and the second chromosome inversions discussed above.

For Est-2, Pept-2 and Aldox, all pair-wise disequilibria were significant. The disequilibrium was stronger between Aldox and Est-2 than between Pept-2 and Est2. This is expected from the position of the three loci relative to the inversions (Fig. 1). Aldox and Est-2 are located within the system of inversions while Pept-2 lies outside all paracentric inversions. As Est-2 is highly associated with inversions, we can predict the associations of Aldox with inversions. Aldox ${ }^{b}$ is associated with $E s t-2^{a}$ and, as a consequence, must be associated with 2 st; meanwhile Aldox ${ }^{a}$ is over-represented in $2 \mathrm{j}, 2 \mathrm{jz}^{3}$ and $2 \mathrm{jq}^{7}$. A study of the composite genotypic disequilibrium between Est-2 and Aldox in Carboneras (Quezada-Díaz, 1993) yielded a correlation coefficient between Est $-2^{a}$ and Aldox ${ }^{a}$ of $-0.0549(P<0.05)$. The direction of the association is thus the same in both populations.

The two populations analysed here are the first in which the gametic associations between Est-2, Pept-2 and Aldox in D. buzzatii have been described. It is clear that more information from other populations, original and colonized, is needed in order to draw a more complete picture of their associations with the second chromosome inversions.

\section{Acknowledgements}

We thank Dr A. Barbadilla, A. Navarro, J. M. Ranz and Dr A. Leibowitz for valuable discussion and criticism. J. M. Ranz kindly provided the TLD program. Work was supported by a F. I. fellowship from the DGU (Generalitat de Catalunya, Spain) to E. B. and grant (PB 89-0325) from the DGICYT (Ministerio de Educación y Ciencia, Spain) to A. F.

\section{References}

BACKeberG, c. 1977. Cactus Lexicon. Enumerative Diagnostica. Cactaccearum. Blandford Press, Poole, England.

BARbadilla, A., RUIZ, A., SANTOS, M. AND FONTDEVILA, A. 1994. Mating pattern and fitness component analysis associated with inversion polymorphism in a natural population of Drosophila buzzatii. Evolution (in press).

BARBADILlA, A., QUEZADA-DIAZ, J. E., RUIZ, A., SANTOS, M. AND FontdeVila, A. 1991. The evolutionary history of Drosophila buzzatii. XVII. Double mating and sperm predominance. Genet. Sel. Evol., 23, 133-140.

BARKER, J. S. F. 1981. Selection at allozyme loci in cactophilic Drosophila. In: Gibson, J. B. and Oakeshott, J. G. (eds) Genetic Studies of Drosophila Populations. Proceedings of the 1979 Kiola Conference, pp. 161-184. Australian National University, Canberra.

BARKER, J. S. F. AND EAST, P. D. 1980. Evidence for selection following perturbation of allozyme frequencies in a natural population of Drosophila. Nature, 284, 166-168.

BARKER, J. S. F., EAST, P. D. AND CHRISTIANSEN, F. B.1989. Estimation of migration from a perturbation experiment in natural populations of Drosophila buzzatii Patterson \& Wheeler. Biol. J. Linn. Soc., 37, 311-334.

BARKER, J. S. F., EAST. P. D. AND WEIR, B. S. 1986 . Temporal and microgeographic variation in allozyme frequencies in a natural population of $D$. buzzatii. Genetics, 112, 577-611.

BARKER, J. S. F., SENE, F., EAST, M. AND PEREIRA, M. A. Q. R. 1985. Allozyme and chromosomal polymorphism of Drosophila buzzatii in Brazil and Argentina. Genetica, 67, 161-170.

BENNET, J. H. 1954. On the theory of random mating. Ann. Eugen., 18, 311-317.

BETRÁN, E. 1992. Efecte del Polimorfisme d'Inversions $i$ Allozímic sobre Caràcters Quantitatius en una Població de Drosophila buzzatii. Master's thesis, Universitat Autònoma de Barcelona.

BMDP. 1988. Statistical Software. University of California Press, Berkeley.

BRITton, N. L. AND Rose, J. N. 1963. The Cactaceae. Dover Publications, New York.

CHARLESWORTH, B. 1974. Inversion polymorphism in a twolocus genetic system. Genet. Res., 23, 259-280.

CROW, J. F. AND KIMURA, M. 1970. An Introduction to Population Genetics Theory. Harper and Row, New York.

CSS Statistica $^{\text {TM }}$ 1991. Statsoft of Europe, Hamburg.

DAVID, J. R. AND BOCQUET, C. 1975. Similarities and differences in latitudinal adaptation of two Drosophila sibling species. Nature, 257, 588-590.

DAVID, J. AND TSACAs, L. 1980. Cosmopolitan, subcosmopolitan and widespread species: different strategies within the Drosophilid family (Diptera). C. R. Soc. Biogéogr., 57, 11-26.

EDLANT-JOHnson, R. C. 1971. Probability Models and Statistical Methods in Genetics. J. Wiley, New York.

FONTDEVILA, A. 1981. Çuánto polimorfismo se pierde en la colonización? Simposia Genética y Ecol. Especiación Animal, pp. 69-99. Universidad Simón Bolivar, Venezuela. 
FONTDEVILA, A. 1989. Founder effects in colonizing populations: the case of Drosophila buzzatii. In: Fontdevila, A. (ed.) Evolutionary Biology of Transient Unstable Populations, pp. 74-95. Springer, Berlin.

FonTdEVILA, A., RUIZ, A., ALONSO, G. AND ocaÑA, J. 1981. The evolutionary history of Drosophila buzzatii. I. Natural chromosomal polymorphism in colonized populations of the Old World. Evolution, 35, 148-157.

FONTDEVIla, A., RUIZ, A., OCAÑA, J. AND ALONSO, G. 1982. The evolutionary history of Drosophila buzzatii. II. How much has polymorphism changed in colonization? Evolution, 36, 843-851.

GAFFNEY, P. M., SCOTT, T. M., KOEHN, R. K. AND DIEHL, W. J. 1990. Interrelations of heterozygosity, growth rate and heterozygote deficiencies in the Coot Clam, Mulinia lateralis. Genetics, 124, 687-699.

HASSÓN, E., FANARA, J. J., RODRIGUEZ, C., VILARDI, J. C., REIG, O. A. AND FONTDEvila, A. 1992. The evolutionary history of Drosophila buzzatii. XXIV. Second chromosome inversions have different average effects on thorax length. Heredity, 68, 557-563.

ISHI, K. AND CHARLESWORTH, B. 1977. Associations between allozyme loci and gene arrangements due to hitch-hiking effects of new inversions. Genet. Res., 30, 93-106.

KNIBB, W. R. AND BARKER, J. S. F. 1988. Polymorphic inversion and esterase loci complex on chromosome 2 of Drosophila buzzatii. II. Spatial variation. Aust. J. Biol. Sci., 41, 239-246.

KNIBB, W. R., EAST, P. D. AND BARKER, J. S. F. 1987. Polymorphic inversion and esterase loci complex on chromosome 2 of Drosophila buzzatii. I. Linkage disequilibria. Aust. J. Biol. Sci., 40, 257-269.

LABRADOR, M., NAVEIRA, H. AND FONTDEVILA, A. 1990. Genetic mapping of the Adh locus in the repleta group of Drosophila by in situ hybridization. J. Hered., 81, 83-86.

LEWONTIN, R. C. 1964. The interaction of selection and linkage. I. General considerations: heterotic models. Genetics, 49, 49-67.

LEWONTIN, R. C. AND KOJIMA, K. 1960. The evolutionary dynamics of complex polymorphisms. Evolution, 14, 458-472.

LOUKAS, M. AND KRIMBAS, C. B. 1980 . Isozyme techniques in Drosophila subobscura. Drosoph. Inf. Serv., 55, 157-158.

LOUKAS, M., KRIMBAS, C. B. AND VERGINI, Y. 1979. The genetics of Drosophila subobscura populations. IX. Studies on linkage disequilibrium in four natural populations. Genetics, 93, 497-523.

MONTCHAMP-MOREAU, C. AND KATZ, M. 1986. A theoretical analysis of linkage disequilibrium produced by genetic drift in Drosophila populations. Genet. Res., 48, 161-166.

NEI, M. AND LI, w. 1980. Non-random association between electromorphs and inversion chromosomes in finite populations. Genet. Res., 35, 65-83.

PAMILO, P. AND VARVIO-AHO, s. 1994. Testing genotype frequencies of heterozygosities. Mar. Biol., 79, 99-100.

PEREIRA, M. A. Q. R., VILELA, C. R. AND SENE, F. M. 1983. Notes on breeding and feeding sites of some species of the repleta group of the genus Drosophila (Diptera, Drosophilidae). Ciência e Cultura, 35, 1313-1319.
PREVOSTI, A. 1955. Variacion geografica de caracteres cuantitativos en poblaciones británicas de Drosophila subobscura. Genét. Ibér., VII, 3-44.

QuezadA-DIAZ, J. E. 1993. Estructura Poblacional y Patrón de Apareamientos de la Especie Cactófila Drosophila buzzatii. Ph.D. Thesis. Universitat Autònoma de Barcelona, Spain.

QUEZADA-DIAZ, J. E., SANTOS, M., RUIZ, A. AND FONTDEVILA, A 1992. The evolutionary history of Drosophila buzzatii. XXV. Random mating in nature. Heredity, 63, 373-379.

ROBINSON, W. P., ASMUSSEN, M. A. AND THOMSON, G. 1991. Threelocus systems impose additional constraints on pairwise disequilibria. Genetics, 129, 925-930.

RUIz, A. 1982. El Polimorfismo de Inversiones en Drosophila buzzatii. Ph.D. Thesis. Universidad de Santiago de Compostela. Santiago de Compostela, Spain.

RUIZ, A. AND FONTDEVILA, A. 1985. The evolutionary history of Drosophila buzzatii. VI. Adaptive chromosomal changes in experimental populations with natural substrates. Genetica, 66, 63-71.

RUIZ, A., FONTDEVILA, A., SANTOS, M., SEOANE, M. AND TORROJA, E. 1986. The evolutionary history of Drosophila buzzatii. VIII. Evidence for endocyclic selection acting on inversion polymorphism in a natural population. Evolution, 40, 740-755.

RUIZ, A., NAVEIRA, H. AND FONTDEVILA, A. 1984. La historia evolutiva de Drosophila buzzatii. IV. Aspectos citogeneticos de su polimorfismo cromosomico. Genét. Ibér., 36, 13-35.

RUIZ, A. AND SANTOS, M. 1989. Mating probability, body size, and inversion polymorphism in a colonizing population of Drosophila buzzatii. In: Fontdevila, A. (ed.) Evolutionary Biology of Transient Unstable Populations, pp. 96-113. Springer, Berlin.

RUIZ, A., SANTOS, M., BARBADILLA, A., QUEZADA-DIAZ, J. E., HASSON, E. AND FONTDEVILA, A. 1991. Genetic variance for body size in a natural population of Drosophila buzzatii. Genetics, 128, 739-750.

RUIZ, A., SANTOS, M. AND Fontdevila, A. 1987. Differential response to environmental alcohol among second-chromosome arrangements in experimental populations of Drosophila buzzatii. Genetica, 75, 219-229.

RUIZ, A. AND WASSERMAN, M. 1993. Evolutionary cytogenetics of the Drosophila buzzatii species complex. Heredity, 70 , 582-596.

SANTOS, M. 1994. Heterozygote deficiencies under Levene's population subdivision structure. Evolution (in press).

SANTOS, M., RUIZ, A., BARBADILLA, A., QUEZADA-DIAZ, J. E. AND FONTDEVILA, A. 1988. The evolutionary history of Drosophila buzzatii. XIV. Larger flies mate more often in nature. Heredity, 61, 255-262.

SANTOS, M., RUIZ, A. AND FONTDEVILA, A. 1989. The evolutionary history of Drosophila buzzatii. XIII. Random differentiation as a partial explanation of chromosomal variation in a structured natural population. Am. Nat., 133, 183-197.

SANTOS, M., RUIZ, A., QUEZADA-DIAZ, J. E., BARBADILLA, A. AND FONTDEVILA, A. 1992. The evolutionary history of Drosophila buzzatii. XX. Positive phenotypic covariance between field adult fitness components and body size. $J$. Evol. Biol., 5, 403-422. 
SCHAFER, D. J., FREDLINE. D. K., KNIBB, W. R., GREEN, M. M. AND BAKER, J. S. F. 1993. Genetics and linkage mapping of Drosophila buzzatii. J. Hered., 84, 188-194.

SLATKIN, M. 1977. Gene flow and genetic drift in a species subject to frequent local extinctions. Theor. Pop. Biol., 12, 253-262.

SOKAL, R. R., ODEN, N. L. AND BARKER, J. S. F. 1987. Spatial structure in Drosophila buzzatii populations: simple and directional spatial autocorrelation. Am. Nat., 129, 122-142.

SOKAL, R. R. AND ROHLF, F. J. 1981. Biometry, 2nd edn. Freeman, New York.

WASSERMAN, M. 1962. Cytological studies of the repleta group of the genus Drosophila. V. The mulleri subgroup. Studies in Genetics. II. Texas University Publishers, 6205, 119-134.
WATT, A. W. 1981 . The genetics of temperature tolerance in Drosophila buzzatii. In: Gibson, J. B. and Oakeshott, J. G. (eds) Genetic Studies of Drosophila Populations. Proceedings of the 1979 Kiola Conference, pp. 139-146. Australian National University, Canberra.

WEIR, B. S. 1990. Genetic Data Analysis. Sinauer, Sunderland, MA.

YAMAGUCHI, O., ICHINOSE, M., MATSUDA, M. AND MUKAI, T. 1980. Linkage disequilibrium in isolated populations of Drosophila melanogaster. Genetics, 96, 507-522.

YAMAZAKI, T. 1977. The effects of overdominance on linkage in a multilocus system. Genetics, 86, 227-236.

zOUROS, E. AND KRIMBAS, C. B. 1973. Evidence for linkage disequilibrium maintained by selection in two natural populations of Drosophila subobscura. Genetics, 73, 659-674. 